\title{
REFLEJOS DE ORALIDAD EN LA CORRESPONDENCIA DEL ILUSTRADO ARAGONÉS DON JOSÉ NICOLÁS DE AZARA
}

\author{
REFLECTIONS OF ORALITY IN THE CORRESPONDENCE OF THE 'ENLIGHTENED' \\ ARAGONESE DON JOSÉ NICOLÁS DE AZARA
}

\section{José M. Enguita Utrilla}

Universidad de Zaragoza

Resumen

El ilustrado aragonés don José Nicolás de Azara pasó gran parte de su vida en Italia (1765-1797), donde llevó a cabo importantes tareas diplomáticas, como revela la lectura del rico Epistolario que, en el desempeño de esas actividades, ha legado a la posteridad. Las cartas redactadas con dicho propósito -como él mismo advirtió- pueden albergar, más allá de los formulismos "oficiales», rasgos expresivos más espontáneos siempre que se den las condiciones adecuadas para ello. Desde este último punto de vista se analizará a continuación una muestra representativa del influjo italiano que en esas «condiciones adecuadas» emerge en su correspondencia.

Palabras clave: José Nicolás de Azara, Epistolario, llustración, formulismo I espontaneidad en los textos epistolares, influencia del italiano sobre el español como reflejo de la oralidad.
Abstract

The 'enlightened' Aragonese Don José Nicolás de Azara spent much of his life in Italy (1765-1797), where he carried out important diplomatic tasks, as revealed by the reading of his rich Epistolario that, in the course of those activities, has reached posterity. The letters written with this purpose -as he warned himself- can contain, beyond the "official» formalities, more spontaneous expressive features if appropriate conditions are met. From this last point of view, the main goal of this paper is to analyse a representative sample of Italian influences that, in these «appropriate conditions», emerge in his correspondence.

KEY WORDS: José Nicolás de Azara, Epistolario, Enlightenment, formality / spontaneity in epistolary texts, influences from Italian to Spanish as a reflection of orality. 


\section{INTRODUCCIÓN}

1. Los estudiosos de don José Nicolás de Azara han destacado de este aragonés nacido en 1730 en Barbuñales (Huesca) su carácter cosmopolita y europeísta y, enlazando con estas cualidades, su participación en actividades que van desde la diplomacia -en cuyo ejercicio ocupó una buena parte de su vida- a la edición de clásicos españoles del siglo $\mathrm{XVI}$, al mecenazgo de empresas arqueológicas, a su pasión por las obras de arte y por el coleccionismo de libros. No me detendré en la rica biografía de don José Nicolás de Azara, actualizada con gran detalle en un libro todavía reciente de Gimeno Puyol (2010)1. Sí destacaré, no obstante, algunos aspectos de su vida que pueden ser de utilidad para interpretar de modo coherente su abundante correspondencia diplómática y también los rasgos formales y estilísticos con que esta se desarrolla. Tras alcanzar el grado de bachiller en Derecho Civil y Canónico en la Universidad Sertoriana de Huesca (1749), pasó al Colegio Mayor de San Salvador de Oviedo en Salamanca -si bien como estudiante "manteísta»²-, donde hizo amistad con otros estudiantes, entre ellos Simón de las Casas o el famoso cardenal Lorenzana; y, como ellos, ocuparía un puesto de relieve en la administración de la España borbónica. De hecho, en 1760 ganó una plaza en la Primera Secretaría del Despacho del Estado en Madrid, para cuya obtención debieron ser relevantes sus conocimientos de latín y francés y, también, aunque en menor medida, de inglés e italiano. Desde este puesto, en 1765 viajó a Italia como Agente General y Procurador del Rey en la Corte de Roma, en unos momentos de relaciones difíciles con el Papado a causa del tema de las regalías y de la disolución de la Orden de los jesuitas, expulsados de España tras el motín de Esquilache (marzo de 1766). Dieciocho años más tarde encabezó la embajada española en Roma hasta 1798. Aún se ocuparía después de la representación de España en París hasta poco antes de su fallecimiento, que tuvo lugar en la capital francesa en 1804.

Esta actividad diplomática, desempeñada durante los reinados de Carlos III y de Carlos IV, y fundamentalmente desde Italia, lo llevó a intervenir, lógicamente, en los asuntos vaticanos -como pone de manifiesto buena parte de su Epistolario-, pero también a relacionarse con el emperador José II de Alemania, con los zares Catalina II y Pedro I de Rusia, con Federico de Prusia, con los Reyes de Suecia y Dinamarca e, incluso, con Napoleón Bonaparte, por lo que pudo conocer de primera mano la situación política de la Europa del momento $y$, por otra parte, intervenir de modo muy activo en acontecimientos importantes de las últimas décadas del siglo XVIII: así, en la controvertida expulsión de los jesuitas de los dominios españoles o en el armisticio de Bolonia que impidió la invasión de los Estados pontificios por las tropas napoleónicas.

\footnotetext{
'Cf. al respecto la "Cronología de Azara» (ibid.: CCXIX-CCXXII) y, en general, el «Estudio preliminar» que encabeza la edición de su Epistolario entre 1784 y 1804 (ibid.: XIII-CCXV). Han tratado asimismo sobre este ilustrado aragonés otros especialistas, entre ellos Corona Baratech (1987) y Olaechea (1987). Cf. además la biografía de este personaje que, con propósito más divulgativo, aparece en la Gran Enciclopedia Aragonesa, firmada por Jordán de Urríes y Azara.

${ }^{2}$ Según el DLE, era la designación que se aplicaba a los estudiantes que asistían a las escuelas públicas vestidos de sotana y manteo: «Se llamaba así a la generalidad de los escolares, para diferenciarlos de los que tenían beca en los colegios mayores». Comenta Gimeno Puyol (2010: XVI) que si José Nicolás de Azara «adquirió luces y participó de la filosofía racionalista, tuvo que hacerlo de manera autodidacta mediante lecturas, con la constante observación a que le incitaba su curiosidad, y a través del intercambio de ideas en la conversación con hombres cultos». Para otros detalles sobre este aspecto, cf. Olaechea (1987: 41-48).
} 


\section{LA ILUSTRACIÓN: RENOVACIÓN Y TRADICIÓN EN EL LÉXICO DE LA LENGUA ESPAÑOLA}

No estará de más recordar -con Rafael Lapesa (1981: 428-429)- que las nuevas orientaciones ideológicas, el interés por las ciencias físicas y naturales, las transformaciones que se iban abriendo paso en la política y en la economía, «pusieron en curso multitud de neologismos, prestaron a voces ya existentes acepciones que antes no tenían, o infundieron valor de actualidad a términos que carecían de él» ${ }^{3}$, actitud a la que se opone el purismo, que rechaza la intromisión de vocablos nuevos, procedentes de otras lenguas o de un creación personal. También surge en el siglo XVIII español una corriente que Álvarez de Miranda (2004: 1052) denomina «obsesión crítica casticista», a la que ya se había referido varias décadas antes Lapesa (1981: 428): «A fuerza de repetir imágenes y conceptos, la literatura se había apartado del habla, y el léxico estaba empobrecido. Los escritores más notables del siglo XVIII pugnaron por recobrar el dominio de la lengua y aumentar el vocabulario disponible»" Purismo y casticismo son -según Lázaro Carreter (1985: 261)- planos distintos, con una arista común:

\footnotetext{
la seguridad de que la lengua española está formada y de que posee una suficiente abundancia de vocablos que le permite desarrollar su vida sin préstamos de otros idiomas. Pero mientras en la vertiente casticista se pugna por remover aquella riqueza inoperante, en la purista se levanta un obstinado muro, que opone su intransigencia a la menor penetración de neologismos.
}

Renovación y tradición que se perciben con claridad en la correspondencia del diplomático aragonés y que le permiten aprovechar en su redacción un número estimable de neologismos acordes con los nuevos tiempos, especialmente referidos a la política, a la culturas y al desarrollo social. Por otra parte, no desdeña introducir en sus escritos epistolares expresiones fijas, refranes y formas léxicas muy arraigadas en la tradición oral de la lengua española. Como se infiere de los comentarios precedentes y -según ha señalado Gimeno Puyol (2010: CLXII) tras el análisis del prólogo a las Obras de Garcilaso de la Vega, que publicó en 1765- Azara se sitúa en el lado de los casticistas, y en su Epistolario,

\footnotetext{
a pesar de los largos períodos ciceronianos de los que tanto gusta, pone en práctica ese ideal en el que conviven la claridad expositiva, la expresión solemne, adornada y atemperada por frases coloquiales, los recursos humorísticos, la selección de un vocabulario que le permite una fluida comunicación de ideas (ibid.: CLVIII).
}

Por otra parte, la presencia de la lengua italiana en las cartas de Azara, que no siempre responde a motivos de necesidad, sino que más bien se manifiesta como recurso expresivo y, en general reflejo del habla espontánea, viene a confirmar -según se comentará a continuación- su rechazo del purismo lingüístico en sentido estricto.

\footnotetext{
${ }^{3}$ Con el siglo XVIII se abre una etapa de intenso enriquecimiento del léxico intelectual y científico, léxico que -como observa Gómez de Enterría (2001: 79-88)- tiene muy diversos grados de penetración en la lengua general: surge, desde luego, en ámbitos limitados, pero a veces se difunde en textos de mayor alcance, como la prensa periódica. Sobre la penetración del léxico ilustrado en la lengua española se han realizado ya numerosas contribuciones, anotadas por Álvarez de Miranda (2004: 1057-1064) en la amplia bibliografía del trabajo que ha dedicado al "Léxico español, desde el siglo XVIII hasta hoy».

${ }^{4}$ No obstante -advierte Lapesa: ibid.-, «prejuicios aristocráticos librescos -tanto más explicables cuanto más profundo había sido el mal del avulgaramiento- impidieron muchas veces que el arte dignificara las aguas vivas de la expresión cotidiana».

${ }^{5}$ En su faceta de crítico de arte, cf. López Mora (2016).
} 


\title{
3 EL CORPUS OBJETO DE ANÁLISIS
}

Los materiales que son objeto de análisis en estas páginas corresponden a un modo discursivo específico, la carta, regulado por una serie de convenciones retóricas y culturales que definen la intertextualidad ${ }^{6}$ del género epistolar, que Álvarez (1995: 11) define como una forma de interacción social «que parte de una situación comunicativa muy especial: uno de los interlocutores no está presente», es decir, "presupone la existencia de una segunda persona» ${ }^{7}$. Desde esa perspectiva, la carta ofrece la posibilidad de incluir formas expresivas espontáneas siempre que se den las condiciones adecuadas para ello. En lo que concierne al Epistolario de Azara, y en general al siglo XVIII, conviene tener en cuenta -según ha sugerido Albiac (2011: 350)que

\begin{abstract}
es sencillo establecer la diferencia entre la correspondencia oficial y administrativa y la privada; en cambio resulta más complicado clasificar otro tipo de cartas, frecuente entre los personajes públicos en el siglo XVIII, que primordialmente dan informaciones políticas, en ocasiones reservadas, pero en las que los autores no se privan de entrar en el ámbito de lo personal.
\end{abstract}

Son las cartas "particulares», que Azara separa de las "cartas de oficio»" las cuales, propiamente, corresponden al lenguaje administrativo. La preferencia del diplomático aragonés por las cartas particulares (así, las dirigidas a amigos como Llaguno e Iriarte, familiares como Bardají, o también a personajes políticos de más confianza, entre los que cabe mencionar a Moñino conde de Floridablanca, Godoy, Cevallos, Saavedra y Urquijo) queda en ocasiones explícitamente justificada por el autor, como se desprende de los siguientes fragmentos:

(1) Podría escribir de oficio todo esto y componer un discurso elegante y relamido, pero a $V$. M. basta lo que llevo dicho y la circunstancia expresada en el estilo de la verdad (a Moñino. 1792.129.217)9.

(2) Nos conviene infinito para el bien de los negocios que nos entendamos reservadamente, pues hay infinidad de cosas que uno calla en las cartas de oficio por respetos humanos. Así, pues, puede Vd. contar con que hallará en mí toda franqueza que puede desear y un hombre a toda prueba (a Saavedra. 1798.413.655).

(3) Aquí me deben de tener todos por sospechoso y apestado, pues fuera de las cartas sequísimas de oficios, ninguno se atreve a escribirme (a Iriarte. 1799. 472.729).

(4) En mi última de oficio dije a Vd. lo bastante para conocer la situación crítica de este Cónsul, y en la particular me explayé más (a Cevallos. 1801.653.967) ${ }^{10}$.

\section{EL COMPONENTE ITALIANO EN EL EPISTOLARIO DE AZARA}

Habrá que interpretar dentro de estas expresiones («estilo de la verdad», «franqueza», «explayarse más»), las cartas que Azara clasifica como «particulares», «confidenciales» o «reservadas» -lejos de los rígidos moldes burocráticos, característicos de las cartas de «oficio»-, que le permiten expresarse con más libertad e introducir elementos

\footnotetext{
${ }^{6}$ Sobre este concepto, vid. Bustos Tovar (2002: 53-56).

7 Acerca de los diversos tipos de carta, vid. Álvarez (1995: 17-26). Cf. asimismo el clásico estudio de Salinas (1986), minuciosamente reseñado por Gimeno Puyol (2010: CXLVII-CLI).

${ }^{8}$ El oficio -según indica Álvarez (1995: 40-41)- es «el medio a través del que se establece la comunicación en el seno de cualquier organismo o entidad oficial, y también puede la Administración, en ocasiones, informar sobre cualquier asunto a sus administrados".

${ }^{9}$ En adelante, los ejemplos extraídos del Epistolario de Azara serán citados mediante la referencia al destinatario (a Aranda), al año de redacción de la carta (1784), al número de documento con que aparece en la edición de Gimeno Puyol (4) y a la página a la que corresponde la palabra o el enunciado citados en dicha edición (17): (a Aranda. 1784.4.7).

${ }^{10}$ Más datos sobre este tema en Gimeno Puyol (2010: CXLVIII-CLI).
} 
lingüísticos más propios del habla viva, los cuales infunden a su discurso mayor expresividad. He aquí algunos ejemplos:

(5) Basta de cháchara inútil. El cardenal de Bernis me encarga mucho saludar a V. E. (a Aranda.1786.19.45).

(6) Si Vd. fuera sicut ceteri homines, le espetaría un cartapacio de palabrotas de gracias por mi sobrino, pero estoy bien lejos de eso (a Moñino. 1791.106.178).

(7) Donde se ha armado una marimorena que no tiene ejemplo en la historia, es en Nápoles (a Aranda. 1785.15.34).

(8) [...] que al principio metían tanto fuego al Papa para que descomulgase a troche y moche, ahora escriben encargando la prudencia (a Moñino.1792.129.215).

(9) Según va el negocio, antes de un año la Europa no la conocerá la madre que la parió (a Iriarte. 1794.190.292).

(10) Navegue el buen señor por la poca agua que Dios le ha dado, y todo quedará compuesto (a Aranda. 1784.4.8).

Ciertamente, el diplomático aragonés acoge en su Epistolario asimismo un rico inventario de neologismos acuñados al hilo de la llustración, sobre todo procedentes del francés (complotar 1786.25.54 'confabularse con fines políticos', sansculottes 1794.190.293 'el grupo más extremista de la Revolución francesa', jacobins 1792.120.196 'miembro del partido republicano durante la Revolución francesa'), del italiano (logia 1790.73.128 'centro de reunión de los masones') y, en menor medida, del inglés (club 1792.120.197 'junta de individuos de una sociedad política, a veces clandestina'), numerosas expresiones latinas (ipso facto 1792.120.197 'en el acto, inmediatamente', in manus tuas domine 1186.18.43 'a tu disposición') e incluso algunas voces ajenas al mundo occidental (por ejemplo, bey 1786.32.64 'gobernador de una ciudad, distrito o región del imperio turco' o czarina 1792.122.201 'esposa del zar').

Interesa prestar atención, para nuestro objeto de análisis, a la presencia del italiano en la correspondencia de Azara: un motivo que pudiera justificar esa presencia podría ser el contagio ejercido por dicha lengua sobre la propia de Azara a lo largo de los muchos años de estancia del aragonés por tierras italianas ${ }^{11}$; esta actitud, en principio, no concuerda con su pensamiento castizo ante los hechos lingüísticos, aunque sí confirma su rechazo al excesivo purismo. Por otra parte, su incorporación a la correspondencia del diplomático aragonés requiere en el destinatario ciertos conocimientos de italiano para interpretar acertadamente no solo las voces y las unidades fraseológicas procedentes de esa lengua, sino también algunos otros enunciados de cierta complejidad de más difícil comprensión. La explicación más razonable, a mi modo de ver, enlaza estos elementos foráneos con el habla informal, espontánea y directa, en consonancia con la separación, ya señalada, que propone Azara entre las cartas de oficio y el «estilo de la verdad». De manera que dichos elementos foráneos adquieren con frecuencia en el texto diversos valores expresivos que van desde la intensificación de su carácter negativo a otros matices como la mordacidad, la ironía o el uso festivo, o incluso la complicidad en la interpretación de los mensajes. Conviene recordar, respecto a los comentarios precedentes, que la sociolingüística ha destacado, en relación con la

\footnotetext{
${ }^{11}$ Cuando, en 1765, llegó a Italia, ya poseía conocimientos de italiano, que debió ir perfeccionando según transcurría el tiempo. De hecho en el Epistolario se incluyen algunas cartas autógrafas redactadas por Azara en esta lengua. Vid. por ejemplo las fechadas el 21 de septiembre de 1896 o el 21 de enero de 1997.
} 
alternancia de lenguas en la interlocución, que esta no solo se utiliza con la mirada puesta en la función referencial, sino que también desempeña otras funciones, como

\begin{abstract}
la conativa, si ello conlleva una mayor implicación del interlocutor en el diálogo [...] y puede favorecer las funciones expresiva y fática y, dependiendo de los casos (hacer gala de ciertas habilidades lingüística o efectuar juegos de palabras), la metalingüística y la poética (López Morales, 2004: 241).
\end{abstract}

\title{
5 El COMPONENTE ITALIANO EN EL EPISTORARIO DE AZARA: PROCEDIMIENTOS DE INCLUSIÓN
}

En la correspondencia del diplomático aragonés se aprecian distintas posibilidades de intercambio entre el español y el italiano. Si nos atenemos a los registros que no constituyen neologismos necesarios, sino transferencias generalmente utilizadas con fines expresivos -objetivo principal de este trabajo-, conviene clasificar las muestras de los ejemplos extraídos en los siguientes tipos.

5.1. Azara proporciona en alguna ocasión diálogos en los que emisor y receptor -en el caso que reproduzco, entre el diplomático y el Papa, en carta enviada a Moñino el 4 de febrero de 1789 (doc. 53, p. 99)-, se sirven de distintos códigos ${ }^{12}$ en lo que el mismo Azara califica como «diálogo cómico» y, por tanto, reproducción directa en la carta de una manifestación de la oralidad:

(11) Entonces, medio riendo le he replicado:

-Cuando este punto está en salvo, lo demás no quiere decir nada, pues todo se reduce a que no vaya el chico a España, como no irá, aunque todas dificultades se allanasen; pues lo que a mí me importa es que Su Santidad no se inquiete ni turbe su salud por culpa mía, etc.

Esto se lo he dicho con un tono tan resuelto que lo ha parado; y, bajando la voz, me ha preguntado:

-E a chi mandaremo in Spagna?

-Al diablo -he respondido yo prontamente-, que no me importa nada.

-E che dirà il conte Mognino?

-Dirá lo que un hombre de bien y que tiene principios deberá decir, y juzgará de la cosa por las piezas originales que yo le enviaré.

-Ma, vedete un poco, caro Don Nicola, se ci fosse qualche essempio...

-No ce n'e bisogno, Santo Padre, ya que el muchacho no ha de ir de ninguna manera a España.

Este diálogo cómico ha seguido mucho rato, hasta [que] viendo que no hallaba modo de convertirme, ha mudado la cara, voz, postura y estilo, y me ha dicho:

-Fini[a]mo, amico mio. lo sono a fare tutto quello che vorrete. Basta che non parliamo più del passato. Entonces yo también he cambiado de estilo, y con suma blandura le he dado a entender lo irregular del empeño que le han hecho tomar.

5.2 Otras veces se descubren enunciados que presentan intercambio de códigos dentro de un mismo acto de habla; es decir, «se yuxtaponen oraciones o fragmentos de oraciones de lenguas diferentes en el discurso de un mismo hablante» (Moreno Fernández 1998: 268). Cierto es que en los fragmentos en italiano frecuentemente no introduce Azara su propio discurso ${ }^{13}$, sino enunciados que corresponden a actos de habla de otros personajes que intervienen en la conversación. La mezcla de español e

\footnotetext{
12 «Alternancia entre actos de habla», según la propuesta de Moreno Fernández (1998: 271).

${ }^{13}$ lo que sí sucede en (11): «-No ce n'e bisogno, Santo Padre, ya que el muchacho no ha de ir de ninguna manera a España»; y asimismo, en los ejemplos (14) y (17)-.
} 
italiano añade énfasis a la exposición, en correspondencia con el mensaje que contienen los textos en italiano:

(12) A mis humildes ofertas han respondido constantemente: andiam per mare (a Aranda. 1785.9.15).

(13) la Reina se alarmó de la osadía de Casas, que cometió el enorme delito de hablar al Rey por tres cuartos de hora sin su licencia ni noticia. Al salir, lo llamó y trató como un trapo, amenazándole seriamente si formaba el proyecto horribili di aprire gli ochi a suo marito (a Aranda. 15.34. 1785.15.34).

(14) Se pidieron estos papeles a Casas cara a cara, y fue tan bribón que no los quiso restituir los papeles, y cara a cara fue amenazado di farli tirare una archibusciata, di farli dare velenno, e di brugiarli la casa (a Aranda. 15.35. 26.10.1785).

(15) Caracioli, por segunda mano, avisa a Buoncompagni que haga que el Papa responda al Rey como quiera que sea, y sin entrar en alegaciones, que él responde que se ajustará a todo; pero de ninguna manera busquen apoyo ni mediación de otras cortes, y esto lo pide per l'amor di Dio. Se ve que han olido la mecha, y que la hermana de Francia informa bien a la de Nápoles (a Moñino. 1788.50.93).

(16) y no hace un mes que su hermana en Cesena ha tenido un golpe de apoplejía. No quiera Dios que tengamos qualche improvissata (a Moñino. 1791.107.181).

(17) uno de estos -el primero- ha prorrumpido en esta proposición: I sovrani ano fatte tante novità contro Roma ch'è ben giusto che Roma l'insegni a che poco tiene la loro au[to]rità. En lo demás es preciso confesar que todo Roma rechina y clama contra e libro [...] (a Moñino. 1792.129. 216).

(18) No me queda más que desear sino que me dejen morir en paz sotto l'aura triunfale del Campidoglio (a Iriarte. 1795.333.496).

(19) «[...] que estoy muy arrepentido de lo que hice y que aquí me tienen, que haré todo lo que quieran y como quieran. Disponete di me», fue su última expresión (a Godoy. 1793.166.263).

5.3. Otras veces, la transferencia de elementos de una lengua a otra se desarrolla en forma de préstamos léxicos, de manera que una palabra se incorpora, con su forma y su significado, a la lengua receptora, sobre todo si se refiere a un objeto o una realidad nuevos; resulta más difícil la definición del préstamo cuando este viene a designar, por motivos como el mayor prestigio de la forma de la lengua fuente, una mayor capacidad para llamar la atención o una mayor expresividad desde el punto de vista del hablante, una realidad que ya cuenta con un término que la denomine en la lengua receptora (cf. Moreno Fernández, 1998: 265-266). En el empleo de las unidades léxicas y de las unidades fraseológicas de origen italiano que revelan los ejemplos extraídos del Epistolario de Azara, no concurre la necesidad de nominación al hilo de la renovación que comporta la cultura de la llustración, sino razones de expresividad. He aquí algunos testimonios:

a) Unidades léxicas:

(20) anoian(se) 'se aburren' (DIt. annoiare): «Por lo que toca a los reyes de Nápoles, todos escriben que se anoian soberanamente con toda su corte» (a Moñino. 1790.90.156).

(21) bachicha 'apelativo que se da a los genoveses' (DIt. baciccia): «Finalmente mi Bachicha se retira del mundo sin que nadie se lo haya acordado ni insinuado» (a Aranda. 1784.6.11) (4. $^{14}$

(22) bayocos 'moneda de cobre de escaso valor que tuvo curso en los estados pontificios hasta 1886' (DIt. baiocco 'dinero' ): «en ella verá Vd. que de los 5454 escudos y 55 bayocos se han consumido 3231,5» (a Lorenzana. 1789, 58.109) ${ }^{15}$.

\footnotetext{
${ }^{14}$ El término se aplica a las personas nacidas en Génova, en este casoal antecesor de Azara en la embajada de Roma. No se incorpora al repertorio léxico académico hasta 1927, lo que indude a pensar que su difusión actual en la América Austral, sobre todo en Argentina, Chile y Uruguay, es reciente, ya que se refiere al 'inmigrante italiano' en general, cambio semántico propiciado sin duda por la afluencia a esa zona de italianos desde las últimas décadas del siglo XIX y comienzos de la centuria siguiente.

${ }^{15}$ Consta ya en Autoridades, de donde ha pasado hasta la más reciente edición del Diccionario académico. Se documenta asimismo en Terreros y, ya antes, en Sobrino (1705), según los datos que aporta el NTLLE.
} 
(23) cacarella 'cagalera' (DIt. cacarella): «yo ando hace días con una cacarella que me ha reducido sin fuerzas para nada» (a Iriarte. 1795.226.335).

(24) cazatas 'cacería' (Dlt. cazzata 'gillipollez'): «en un uniforme con que se visten S. M. y los que le acompañan en sus cazatas por toda aquella Alemania» (A Moñino. 1790.91.158)16.

(25) collón 'cobarde, pusilánime, sin valor ni espíritu' (Dlt. coglione 'testículo', fig. 'gilipollas'): «como se lo dan a todo collón de autor» (a Llaguno.1788.45.82); «de ese Malo que está con el patriarca de los collones» (a Llaguno. 1788.45.83) ${ }^{17}$.

(26) fachendear 'hacer ostentación vanidosa o jactanciosa' (DIt. der. de faccenda 'asunto'): «Los agentes del cardenal de Rohan van aquí fachendeando y diciendo que de un correo a otro vendrán los poderes a este prelado Albani para solicitar la justificación consabida» (a Aranda.1786.34.66) ${ }^{18}$.

(27) furfante 'pícaro, pillo, bribón' (DIt. furfante 'canalla, malhechor'): «En cuanto a Vladagni es constante que es un furfante, y sobran ya pruebas de ello» (a Moñino. 1785.11.19); furfantería 'bribonería' (DIt. furfanteria 'bribonería, vileza'): «y que estos dos abates son la nata y la flor de la furfantería» (a Aranda. 1786.34.67) $)^{19}$.

(28) lazareto 'leprosería', 'establecimiento sanitario para aislar a los infectados o sospehosos de enfermedades contagiosas' (Dlt. lazzaretto 'leprosería', 'zona de cuarentena'): «Campitos está como un apestado en el lazareto. Hay orden general para no hablarle» (a Aranda.1786.20.46) ${ }^{20}$.

(29) Madona 'Virgen del Pilar' (it. madonna 'Nuestra Señora'): «y considero a mi paisana la Madona en evidente peligro de ser profanada por aquellos enemigos brutales» (a Iriarte. 1794. 186.288)

(30) mancha 'propina' (it. mancia): "que solo la piel vale la mancha que cuesta» (a Lorenzana. 1790.74.129).

(31) palletas 'tipo meridional de leguleyo astuto' (DIt. paglietta 'sombrero'): «pero De Marco y los palletas quisieron aprovechar este pretexto para dar esta mortificación a Roma y poner ese embarazo de más a la composición de los negocios» (a Moñino.788.50.91) 22.

(32) pranzos 'almuerzo, comida, banquete' (DIt. pranzo): "porque es una semana muy enredada de secaturas y pranzos» (a Moñino. 1790. 76.132).

(33) pretes 'curas, sacerdotes' (DIt. prete): «Casas se dispone también para partir, pero este para Venecia con Campitos, y así me abandonan en medio de los pretes» (a Aranda. 1786.26.56)»; "pues estos pretes comienzan a tener juicio bastante para conocer que no les conviene hacer el papel que hacían antaño» (a Aranda. 1787.39.73).

(34) rallegrarsi 'alegrarse, regocijarse' (DIt. rallegrarsi): «será necesario dar refresco a todos los yentes y vinientes secatores que vienen a rallegrarsi con los candidatos» (a Moñino. 1792.122.202).

(35) retardar 'retrasar' (DIt. ritardare): «No son los vientos ni el mar que los retardan, sino la providencia de Dios y de nuestros argonautas» (a Iriarte. 1794.190.291); retardo 'retraso' (it. ritardo): «La carta de Vd. de 2 del corriente no llegó hasta el sábado cuasi a medianoche, que quiere decir con un retardo de cuatro días» (a Moñino. 1790.91.158) ${ }^{23}$.

(36) ringrazio 'agradecer' (Dlt. ringraziare): «Agradezco gustoso, e ringrazio, la corrección geográfica de "los Pirineos aquende", y no sé cómo se me pudo escapar tal errata, porque es punto que lo tengo muy estudiado y vivido» (a Aranda. 1784.6.11).

\footnotetext{
${ }^{16}$ Sugiere Gimeno Puyol (2009: 158) que esta voz surge de la combinación humorística de dos vocablos italianos: caccia 'caza' y cazzata 'estupidez o tontería'. La voz se registra tardíamente en las obras lexicofráficas, concretamente en Toro y Gómez (1901) y en la Academia (1925), según el NTLLE.

${ }^{17}$ EL DECH, s. v. cojón, señala que el término, de origen italiano, pudo pasar al español por conducto del francés coïon 'hombre flojo y sin energía', donde se registra en 1560. En el caso de Azara no es necesario dicho punto de partida, por su conocimiento directo del italiano y por sus vivencias en Italia. Consta ya en Terreros y en el Diccionario académico desde 1837; el DLE mantiene esta voz de uso coloquial con el valor de 'cobarde'.

18 El DRAE incluye en 1803 esta palabra, que ha mantenido hasta su edición actual (DLE); para otros datos, cf. NTLLE.

${ }^{19}$ A pesar de su empleo frecuente en la correspondencia de Azara, estas voces no constan en la Academia ni en Terreros.

${ }^{20}$ Ya consta en Autoridades y en Terreros (cf. NTLLE) y sigue en el DLE con las dos acepciones apuntadas.

${ }^{21}$ En Autoridades desde 1734, y en 1825 en Núñez de Taboada, según el NTLLE. El DLE mantiene la voz con el significado de 'Nuestra Señora'.

${ }^{22}$ Usaban un sombrero de paja, de ahí la acepción figurada de la voz paglietta aplicada a dichos personajes. Vid. al respecto Gimeno Puyol (2009: 91), quien aduce la oportuna bibliografía.

${ }^{23}$ Según el DECH, el término retardar, documentado ya en Autoridades, fue tomado del francés; el registro lexicográfico de retardo es más tardío (1822 en la Academia, 1852 en Núñez de Taboada, según el NTLLE); sin embargo, su apreciable presencia en el Epistolario de Azara -si bien también constan los sinónimos españoles retrasar y retraso- hace pensar en un origen italiano. El DLE recoge retardar y retardo sin plantearse más que su filiación latina.
} 
(37) scelerata 'infame, malo' (Dlt. scellerato): «y aunque sea obra scelerata, es preciso tenerla» (a Llaguno. 1788.46.85 $)^{24}$.

(38) secar 'molestar, aburrir' (Dlt. seccare): «y no le seco más que para repetirme a sus órdenes como siempre» (a Aranda. 1786.29.61); secatores 'pelmazos' (DIt. seccatori): «será necesario dar refresco a todos los yentes y vinientes secatores» (a Moñino. 1792.122.202); secatura 'fastidio, molestia' (DIt. seccatura): "[...] me proponía escribir a V. E. y la inmensidad de secaturas me lo ha impedido» (a Aranda. 1787.39.73) ${ }^{25}$.

(39) sólitas, sólitos 'habitual, de siempre, de costumbre' (DIt. solito): «La Princesa ya hacía sus sólitos almanaques» (a Moñino. 1790.86.151); «y luego tuvo que leer por tres horas las listas sólitas de tantos obispados» (a Moñino. 1792.129.215) ${ }^{26}$.

(40) vilegiar 'veranear' (Dlt. villeggiare): «que está allí a vilegian» (a Godoy. 1794.197.302); vilegiatura 'veraneo' (it. villeggiatura): «escrita ya en París después de la larga vilegiatura de los Pirineos» (a Aranda. 1785.15.34).

\section{a) Unidades fraseológicas:}

(41) a rota di collo 'precipitadamente, con mucha prisa ' (DIt. a rotta di collo 'a toda pastilla'): «Las cosas de la guerra no van tampoco de manera que puedan ponerse de buen humor pues, como Vd. sabrá, aquello va a rota di collo como dicen aquí» (a Moñino. 1788.50.90).

(42) a vele gonfie 'a toda vela', figuradamente, 'entregándose enteramente o con ansia y toda diligencia a la ejecución de algo' (DIt. a gonfie vele 'a velas desplegadas', 'viento en popa'): «me ponga a los pies de la para mí incógnita nueva Caballera, y mande a vele gonfie a su más afectísimo amigo y servidor» (a Aranda. 1788.49.89).

(43) al fatto 'al corriente, al tanto' (DIt. fatto 'hecho'): «Esto me hace creer que estabas al fatto de la expedición» (a Iriarte. 1799.477.735).

(44) al sólito 'según la costumbre' (DIt. come al solito 'como de costumbre'): «Nuestro cónsul de Bastia se ha portado muy bien y el de Nápoles, al sólito de su nación, como informa el mismo correo no obstante ser napolitano» (a Moñino. 1792.122.200).

(45) buone feste! '¡felices fiestas! (DIt. buone feste! 'jfelices fiestas!'): «Ahí le remito a Vd. ese breve del Papa di buene feste, que solo la piel vale la mancha que cuesta» (a Lorenzana. 1790.74.129).

(46) calare le braghe 'bajarse los pantalones' (Dlt. calare le brache 'bajarse los pantalones'): «Estamos llenos de relaciones de lo q[ue] pasa en Coblenza, que hacen -com[o] dicen aquí-calare le braghe. Los dos príncipes están a punto de romper, no por ellos sino por sus malditas maitresas, que son un par de locas desatinadas de lo que no hay» (a Moñino. 1792.127.210).

(47) e viva! '!y vivaj' (Dlt. viva! '!vivaj): «habrá cisma declarado. Nosotros por el hecho quedaremos descomulgados. E viva!» (a Iriarte. 1797.333.496).

(48) fotuta vita 'jodida vida' (DIt. fotuto 'jodido'): «Esta mañana he venido a la cama a las cuatro, habiendo asistido a una gran cena sin cenar, y a un gran baile sin bailar. Fotuta vita, pero que no tiene remedio todavía» (a Llaguno. 1788.46.84).

(49) in petto 'en el corazón' (DIt. avere un segreto in petto 'tener un secreto en el corazón'): «Minuci, arzobispo de Feltre y amigo del Papa in minoribus, está reservado in petto hace diecisiete años» (a Lorenzana. 1795.205.311).

(50) tanto meglio 'tanto mejor' (Dlt. tanto meglio 'mejor que mejor', 'mucho mejor'): «Aquí me deben de tener todos por sospechoso y apestado, pues fuera de las cartas sequísimas de oficios, ninguno se atreve a escribirme. Tanto meglio» (a Iriarte. 1799.472.729).

5.3.1. Cabe destacar -como ya se ha señalado en comentarios precedentes- que, los testimonios léxicos, seleccionados entre los que se sitúan más próximos a la oralidadescasa relación guardan con los avances científicos y sociales desarrollados al hilo de la llustración, asunto al que ya se ha referido Álvarez de Miranda (2009: 29), al comentar

\footnotetext{
${ }^{24}$ Voz que registra la Academia en 1803 y que el DLE mantiene, aunque ya como desusada, con la acepción de 'malvado'. ${ }^{25}$ De todos estos términos -según apunta el DECH-, la Academia introduce en 1843 secatura, palabra que sigue anotada con la acepción de 'insulsez, fastidio' en el DEL, obra en la que también constan el verbo secar y losderivados secante y secatón, con acepciones que se inscriben en dicha área de significado. En Terreros se registra únicamente, en relación con esta familia léxica, secatura.

${ }^{26}$ La Academia recoge esta voz ya en Autoridades, y la ha mantenido hasta nuestros días; se atestigua también en Terreros.
} 
el recorrido de voces como fachenda y secar -precisamente dos familias léxicas ampliamente representadas en las cartas de Azara-:

\begin{abstract}
[...] en realidad, lo que muestra de un modo más elocuente la efectividad de los contactos lingüísticos hispano-italianos es el hecho de que se produzcan préstamos léxicos no ya en aquellos casos en que es preciso designar nuevas realidades o referentes vinculados con todo aquello en que Italia destacaba (préstamos lingüístico-culturales, podríamos denominarlos), sino también [...] en la adopción de voces cotidianas no estrictamente imprescindibles, por no designadoras de realidades nuevas ${ }^{27}$.
\end{abstract}

Constituyen propiamente -si utilizamos la terminología propuesta por Moreno Fernández 1998: 266)- "préstamos espontáneos», fruto de un uso individual, frente a los «préstamos estables», aceptados por toda una comunidad o parte de ella. De hecho, solo unos cuantos pasaron a algunas obras lexicográficas y siguen registrados en el Diccionario académico, si bien con escasa vitalidad ${ }^{28}$. Pertenecen estos vocablos al habla cotidiana (bachicha, bayoco, mancha, palletas, pranzo, pretes, rallegrarsi, retardar y retardo, ringrazio, sólito, vilegiar y vilegiatura; a rota di collo, a vele gonfie, al fatto, al sólito, buone feste!, in petto, tanto meglio) y, con frecuencia, aluden a valoraciones negativas (se anoian, collón, escelerado, fachendear, furfante, lazareto, secar, secatores y secatura; calare le braghe), aunque también podemos considerar en ellos otros matices como la ironía (cazatas; e viva!, fotuta vita), el eufemismo (cacarella) o el humor (Madona).

5.3.2. Ya para terminar, cabe señalar que los préstamos suelen experimentar procesos de adaptación con el fin de ajustarse a las propiedades estructurales de la lengua receptora:

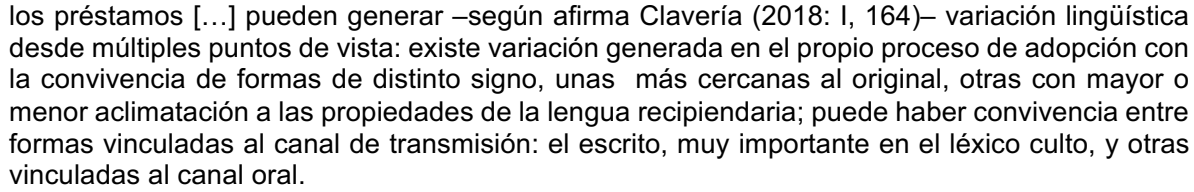
desde múltiples puntos de vista: existe variación generada en el propio proceso de adopción con la convivencia de formas de distinto signo, unas más cercanas al original, otras con mayor o menor aclimatación a las propiedades de la lengua recipiendaria; puede haber convivencia entre formas vinculadas al canal de transmisión: el escrito, muy importante en el léxico culto, y otras vinculadas al canal oral.

El Epistolario de Azara pertenece, por su propia idiosincrasia, al canal escrito y, en él, los italianismos léxicos conservan intacta en pocos casos la ortografía original (cacarella, furfante y furfanteria, rallegrarsi, ringrazio, scelerata, sólito, y en todas las unidades fraseológicas, excepto en calare le braghe), ortografía que otras veces convive con modificaciones -no aplicadas sistemáticamente a todos los registros en que cabe esperar soluciones idénticas- que tratan de representar la pronunciación y la morfología de la lengua receptora: en el primer caso, encontramos la ausencia de vocal palatal final (collón < coglione, secar < seccare, vilegiar < villeggiare); la sustitución i por y (bayocos $<$ baiocco) o por e (retardo < ritardo), de gl por Il (collón < coglione, palletas < paglietta), de ce, ci por ch (bacicha < baciccia, fachendear < faccenda, mancha < mancia); la simplificación de consonantes geminadas (se anoian < annoiano, bachicha < baciccia, bayoco < baiocco, cazatas < cazzata, fachendear < faccenda, lazareto < lazzaretto, Madona < madonna, palletas < paglietta, scelerata < scellerata, secar < seccare,

\footnotetext{
${ }^{27}$ Se lamenta el acreditado lexicógrafo del escaso interés que ha suscitado el estudio de este tema hasta tiempos recientes, cuando hay sobradas pruebas de «un contacto vital y literario entre dos culturas y dos comunidades de hablantes que siempre han estado estrechamente relacionadas". Además, sin negar el contingente de galicismos que se introduce en español a lo largo del siglo XVIII, sitúa en segundo lugar de importancia al italiano, y en tercera posición -a bastante distanciaal inglés (ibid.: 1-2).

${ }^{28} \mathrm{Sin}$ olvidar las circunstancias que, en algunos casos, han concurrido en su pervivencia hasta nuestros días.
} 
secatores < seccatori, secatura < seccatura, vilegiar < villeggiare, villeggiatura < villeggiatura); o la sonorización de oclusivas sordas intervocálicas (braghe < brache); en el segundo, la adición de marcas de plural (bayocos < baiochi, cazatas < cazzate, palletas < pagliette, pranzos < pranzi, pretes < preti, secatores < seccatori, sólitas, sólitos < solite, soliti); la formación verbal en -ear (fachendear); o la acomodación del sufijo flexivo de $3 .^{a}$ del plural del presente de indicativo a las reglas de la lengua española ( se anoian < annoiano, retardan < ritardano).

\section{CONSIDERACIONES FINALES}

El Epistolario de Azara constituye un rico venero para acercarse a las innovaciones léxicas que derivan del pensamiento de la llustración. Aunque no solo eso: con el propósito de llegar más espontáneamente a sus interlocutores, el diplomático aragonés muestra su preferencia, frente a los escritos de oficio, por las cartas personales, en las que se dirige a ellos con mayor familiaridad. No resulta difícil, en este sentido, descubrir en el Epistolario numerosas voces y unidades lexicográficas que corresponden al habla coloquial coetánea; desde esta perspectiva, interesa resaltar también que su conocimiento de la lengua italiana y, sobre todo, el contacto diario con esta lengua durante más de tres décadas, son motivos que, sin duda, favorecen su presencia en la correspondencia de Azara por motivos diferentes: el traslado de diálogos entre interlocutores que se sirven de distintos códigos lingüísticos; la aparición, en un mismo acto de habla, de enunciados en español y en italiano, si bien estos últimos corresponden más frecuentemente a locutores distintos del emisor de los textos; y sobre todo, la incorporación de un número estimable de términos y unidades fraseológicas en el idiolecto de Azara, que en muy pocos casos han llegado a consolidarse en el vocabulario general del español, incluso cuando dan muestras de adaptación a la ortografía, a la fonética y a la gramática el español. Podemos considerar todos esos testimonios como reflejos de oralidad en su Epistolario desde una actitud ciertamente no purista, pues su empleo es innecesario, dado que el español dispone de elementos semánticamente equivalentes. El empleo de esos componentes foráneos en las cartas del diplomático aragonés infunde a su discurso espontaneidad y expresividad, ya que con ese proceder se intensifica el carácter negativo que muchos de ellos poseen o se introducen en la exposición matices como la mordacidad, la ironía o el carácter festivo del relato. Pero la presencia italiana en el Epistolario del diplomático aragonés ofrece todavía muchos alicientes que en esta contribución no han podido ser desvelados, de modo que las conclusiones apuntadas solo considerarse provisionales.

\section{REFERENCIAS BIBLIOGRÁFICAS}

Albiac, María Dolores (2011): Historia de la literatura española. 4. Razón y sentimiento. El siglo de las Luces, Barcelona, Crítica.

Álvarez, Miriam (1995): Tipos de escrito III: epistolar, administrativo y jurídico, Madrid, Arco Libros.

Álvarez DE MiRAnda, Pedro (2005): «Léxico español, desde el siglo XVIII hasta hoy», en Rafael Cano, ed., Historia de la lengua española, Barcelona, Ariel, 2. ${ }^{a}$ ed., 10371064.
Álvarez de Miranda, Pedro (2009): «Sobre los italianismos en el español del siglo XVIII», Dieciocho: Hispanic Enlightenment, 32/2, 1947. Consultado a través de $<w w w$. fundacionramonmenendezpidal.org > [febrero de 2019].

ARQUÉs, Rossend y Adriana PADOAN (2012): II grande dizionario di spagnolo. Dizionario spagnolo-italiano / italiano-español, Bolonia, Zanichelli Editore, 2012. 
AZARA, José Nicolás de (2010): Epistolario (17841804). Estudio, edición y notas de María Dolores Gimeno Puyol, Madrid, Editorial Castalia, Nueva Biblioteca de Erudición y Crítica.

Bustos Tovar, José Jesús de (2002): «Mecanismos de cohesión discursiva en castellano a fines de la Edad Media», en ECHENIQUe Elizondo, M. a Teresa y Juan SÁNCHEZ MÉNDEZ, eds., Actas del I Congreso Internacional de Historia de la Lengua Española, 2 vols., Madrid, Editorial Gredos, I, 53-84.

CLAVERÍA NADAL, Gloria (2018): «Contribución a la historia de los procesos de adaptación en los préstamos del español moderno», en ARNAL Purroy, M. ${ }^{a}$ Luisa et alii, eds., Actas del $X$ Congreso Internacioal de Historia de la Lengua Española, 2 vols., Zaragoza, Institución Fernando el Católico, I, 157-191.

COROMINAS, Juan, con la colaboración de José Antonio PAsCUAL (1980.1991): Diccionario crítico etimológico castellano e hispánico, 6 vols., Madrid, Gredos.

DECH: vid. COROMINAS, Juan.

DIT.: vid. ARQUÉS, Rossend y Adriana PADOAN (2102).

GÓMEZ DE ENTERRÍA, Josefa (2001): «Neologismos que llegan hasta el español de la segunda mitad del siglo XVIII a través de los textos de la divulgación científica», en Jenny Brumme, ed., Actas del II Coloquio Internacional. La historia de los lenguajes iberorrománicos de especialidad: la divulgación de la Ciencia, Frankfurt/Madrid, Vervuert/lberoamericana, 79-88.

GEA (1980-): «Azara, José Nicolás», en Gran Enciclopedia Aragonesa, Zaragoza, Unión
Aragonesa del Libro, II, 348-349. La entrada está firmada por Jaime Jordán de Urríes y Azara.

GIMENo PuYol, María Dolores (2010): «Estudio, edición y notas» del Epistolario de José Nicolás de Azara (1784-1804), Madrid, Editorial Castalia, Nueva Biblioteca de Erudición y Crítica, XIII-CCXXII.

LAPESA, Rafael (1981): Historia de la lengua española, Madrid, Gredos, 9. ${ }^{a}$ ed.

LÁZARO CARRETER, Fernando (1985 [1949]): Las ideas lingüísticas en España durante el siglo XVIII, Barcelona, Editorial Crítica.

LÓPEZ MORA, Pilar (2016): «Aportación a la historia del léxico del s. XVIII: análisis de las Obras de Mengs de D. José Nicolás de Azara», Dicenda. Cuadernos de Filología Hispánica, 34, 215-259.

LÓPEZ MORALES, Humberto (2004): Sociolingüística, Madrid, Gredos, $3 .^{\mathrm{a}} \mathrm{ed}$. aumentada.

MoREno FernándeZ, Francisco (1998): Principios de sociolingüística y sociología del lenguaje, Barcelona, Ariel Lingüística.

NTLLE: vid. Real Academia Española (2001).

OlAECHEA, Rafael (1987): «José Nicolás de Azara: literato y mecenas», en Actas del I Symposium de llustración Aragonesa, Zaragoza, Diputación General de Aragón, 4188.

Real Academia Española (2001): Nuevo tesoro lexicográfico de la lengua española, <www.rae.es> [febrero de 2019].

ReAl AcADEMIA Española (2014): Diccionario de la lengua española, Madrid, Espasa, 23. ${ }^{a}$ ed.

SAlinas, Pedro (1984): «Defensa de la carta misiva y de la correspondencia epistolar», en El Defensor, Madrid, Alianza Tres, 17-113. 